\title{
The dynamics of mergers and acquisitions it
}

\author{
Erwan Morellec $^{\mathrm{a}, \mathrm{b}, \mathrm{c}, *}$, Alexei Zhdanov ${ }^{\mathrm{d}}$ \\ ${ }^{a}$ University of Lausanne, Ecole des HEC, Route de Chavannes 33, 1007 Lausanne, Switzerland \\ ${ }^{\mathrm{b}}$ FAME, Switzerland \\ ${ }^{\mathrm{c}}$ CEPR, London, $U K$ \\ ${ }^{\mathrm{d}}$ Simon School of Business, University of Rochester, Rochester, NY 14627, USA
}

Received 29 April 2003; received in revised form 22 September 2004; accepted 28 October 2004

Available online 23 June 2005

\begin{abstract}
This paper presents a dynamic model of takeovers based on the stock market valuations of merging firms. The model incorporates competition and imperfect information and determines the terms and timing of takeovers by solving option exercise games between bidding and target shareholders. The implications of the model for returns to stockholders are consistent with the available evidence. In addition, the model generates new predictions relating these returns to the drift, volatility and correlation coefficient of the bidder and the target stock returns and to the dispersion of beliefs regarding the benefits of the takeover.
\end{abstract}

(C) 2005 Elsevier B.V. All rights reserved.

JEL classification: G13; G34

Keywords: Takeovers; Real options; Competition; Learning.

\footnotetext{
This paper builds on a paper titled "A Dynamic Analysis of Takeover Deals with Competition and Imperfect Information." We thank Mike Barclay, Ernst-Ludwig Von Thadden, and the associate editor for helpful comments. We also thank the referee for providing detailed comments and suggesting the solution method to the equilibrium with competition. The first author acknowledges financial support from FAME and from NCCR FINRISK of the Swiss National Science Foundation. Part of this research was done when Morellec was on the faculty of the Simon School of Business at the University of Rochester.

${ }^{*}$ Corresponding author. University of Lausanne, Ecole des HEC, Route de Chavannes 33, 1007 Lausanne, Switzerland. Tel.: + $41(0) 216923357$; fax: + $41(0) 216923435$.

E-mail address: erwan.morellec@unil.ch (E. Morellec).
} 


\section{Introduction}

Mergers and acquisitions have been the subject of considerable research in financial economics. Yet, despite the substantial development of this literature, it is still unclear what is the relation between the timing and the terms of takeovers or what are the determinants of returns to shareholders in control transactions. In the vast majority of takeover models, the timing of the takeover is set exogenously and is independent of the negotiated terms of the takeover. The present paper develops an equilibrium framework for the joint determination of the timing and terms of takeovers in the presence of competition and imperfect information. This framework is then used to derive implications regarding returns to stockholders in takeover deals.

The model developed in the paper relies on two key elements. The first is an analogy between takeover opportunities and exchange options. This analogy recognizes that takeover deals typically present participants in the deal with an option to exchange one asset (the shares in the initial firm) for another (shares in the new firm or cash). As shown in the paper, this first element is sufficient to generate implications regarding the timing and the terms of takeovers. In particular, the timing and terms of the takeover are the outcome of an option exercise game in which each firm determines an exercise strategy for its exchange option, while taking into account the other firms' exercise strategies (see also Grenadier, 2002; NovyMarx, 2003).

The second key element of the model relates to the information set of investors. While participating firms have complete information about the underlying parameters of the model, outside investors have incomplete information. However, investors can update their beliefs by observing the behavior of participating firms. This learning process implies that outside investors can anticipate the timing and terms of the takeover to some extent. As a result, the stock market valuations of participating firms reflect the fraction of the takeover surplus that can be captured by public information. This process also implies that as the takeover becomes more likely, a larger fraction of the takeover surplus gets incorporated in the stock market valuations of participating firms, thereby inducing a pre-bid runup in stock prices. The paper also demonstrates that in equilibrium, part of the uncertainty remains unresolved until the announcement of the takeover. Therefore, the model generates abnormal returns to stockholders around takeover announcements.

The derivation of the results in the paper proceeds in two steps. The first step determines the equilibrium restructuring strategy as the solution to an option exercise game between bidding and target shareholders. The second step characterizes the implications of the equilibrium for abnormal returns around takeover announcements. The model generates implications that are consistent with the available empirical evidence and yields a number of new predictions. Notably, the model predicts that (1) abnormal returns to target shareholders should be larger than returns to bidding shareholders; (2) abnormal returns to bidding shareholders can be negative if there is competition for the acquisition of the target; (3) the probability of negative abnormal returns increases with the dispersion of beliefs 
regarding the synergy created by the takeover; (4) abnormal returns to stockholders increase with the volatility of stock returns and decrease with the correlation between the returns of merging firms; (5) the sensitivity to the return characteristics of merging firms is greater for abnormal returns to target shareholders; and (6) competition speeds up the acquisition process and decreases returns to bidding shareholders.

One important prediction of the model is that combined returns to stockholders should be positive since takeovers create wealth in the short run. In that respect our model differs from the hubris hypothesis developed by Roll (1986), which predicts that acquisitions announcements should have a zero combined abnormal return since acquisitions just result in a wealth transfer between bidding and target stockholders. It also differs from the free cash flow hypothesis of Jensen (1986), which predicts that combined returns should be negative. Importantly, our model also allows us to relate stockholder returns to the dispersion of analysts' forecasts and the characteristics of stock returns. These additional predictions are unique to our model.

The analysis in the present paper relates to several articles in the literature. Margrabe (1978) is the first to analyze takeovers as exchange options. In his model, the takeover involves a zero-sum game and timing is exogenous. Shleifer and Vishny (2003) also consider a zero-sum game (in the long run) with exogenous timing. In their framework, outside investors do not incorporate the potential surplus associated with the takeover in the stock market valuations of participating firms. Therefore, the announcement of a takeover generates abnormal announcement returns. The present paper extends these models in several important dimensions. First, the timing and the terms of the takeover are determined endogenously as the solution to an option exercise game. Second, the model incorporates both imperfect information and learning, thereby generating both a pre-bid runup in stock prices and abnormal returns to bidding and target shareholders around the takeover announcement. Finally, we examine the impact of competition on the timing and terms of the takeover.

The paper that is most closely related to the present analysis is Lambrecht (2004). Lambrecht also analyzes takeovers using a real options setting with endogenous timing. One essential difference between the two papers is that his analysis relies on a strong form of market efficiency. This implies that in his model the prices of the companies move smoothly to their post-merger value and there are no abnormal stock returns on the announcement of the takeover. Another important point of departure is that we examine the impact of competition on the timing and terms of takeovers. As shown in the paper, this feature is essential in generating negative announcement returns to the bidder. Finally, we construct a two-factor model that allows for different degrees of correlation between the bidder and target stock returns, whereas Lambrecht considers a one factor model that mostly applies to horizontal mergers. Our paper thus extends and complements the results derived in Lambrecht (2004).

The rest of the paper is organized as follows. Section 2 presents the basic model of takeovers. Section 3 analyzes the dynamics of mergers when there exists a unique bidder. Section 4 introduces competition for the target. Section 5 concludes. 


\section{A reduced-form model of takeovers}

This section presents the basic model and derives preliminary results in a static framework. Throughout the analysis, agents are risk-neutral and the risk-free rate $r$ is constant. Time is continuous and uncertainty is modeled by a complete probability space $(\Omega, \mathscr{F}, \mathscr{P})$.

Consider two firms with capital stocks $K$ and $Q$ and stock market valuations per unit of capital $B$ and $T$. Suppose that the stock market valuation of each firm has two components. The first component is the present value of the cash flows generated by their core businesses, denoted by $X$ and $Y$. The second component is the potential surplus associated with a control transaction, denoted by $G$. In particular, we have

$$
B=X+G_{\mathrm{B}}(X, Y) \text { and } T=Y+G_{\mathrm{T}}(X, Y),
$$

where $X$ and $Y$ are stochastic processes with dynamics defined below.

At any time $t>0$, these two firms can negotiate a takeover deal. We follow Shleifer and Vishny (2003) in assuming that, after the takeover, the value of equity per unit of capital is a linear combination of pre-takeover values. In particular, the posttakeover value of the firm is given by

$$
V(X, Y)=(K+Q)[(\theta+\alpha+\alpha(\omega-1)) X+(1-\theta-\alpha) Y],
$$

where $\theta=K /(K+Q)$ and $(\alpha, \omega) \in \mathbb{R}_{++}^{2}$. As will become clear below, the takeover gain increases with the synergy factor $\alpha$. In addition, $B$ and $T$ are respectively the bidding firm and the target firm when $\alpha$ is positive, which is the case considered in the paper. We assume that $\alpha$ is observable to all investors. By contrast, $\omega$ is only observable to the managers of participating firms. Other market participants do not know this value and assume that it is a random variable. Because insider trading laws (and possibly wealth constraints) prohibit managers from trading on their inside information, we assume that managers do not sell or buy their own stock to restore efficient pricing. Thus, the stock price reflects the information set of the uninformed shareholders. Shareholders decide to accept or reject takeover bids based on the informed manager's recommendation. Thus, when managers recommend a takeover, information is revealed and the stock price reacts. But an outsider does not learn anything new simply by buying shares.

At the time of the takeover, the takeover surplus equals the value of the combined firm minus the sum of the market values of the two firms prior to the takeover. After simplifications, this combined surplus can be expressed as ${ }^{1}$

$$
G^{\mathrm{C}}(X, Y)=(K+Q) \alpha(\omega X-Y) .
$$

\footnotetext{
${ }^{1}$ In the numerical examples below, we will assume that the true value of $\omega$ is $\omega=1$. Because the managers know that the true value of $\omega$, it does not matter whether we multiply the bidder valuation or the target valuation by the factor $\omega$. Notably, we could assume instead that firm value satisfies

$$
V(X, Y)=(K+Q)[(\theta+\alpha) X+(1-\theta-\alpha-\alpha(\omega-1)) Y]
$$

so that the combined gain is given by
} 
Eq. (3) suggests that acquiring firms are better performers $(X>Y)$ and that the restructuring will result in a more efficient allocation of resources. This specification is consistent with the fact that acquirers generally have higher Tobin's $q$ than their target companies (see Andrade and Stafford, 2004).

The restructuring strategy selected by the participants in the deal typically depends on the combined takeover surplus as well as its allocation among participants. Suppose that the takeover agreement specifies that a fraction $\xi$ of the new firm accrues to bidding shareholders after the takeover. (The allocation of the surplus is determined endogenously below.) Such a restructuring opportunity presents bidding shareholders with an option to exchange their initial shares for a fraction $\xi$ of the shares of the combined firm. It also implies that the surplus that bidding shareholders extract from the restructuring satisfies $\xi V(X, Y)-K X$, or

$$
G^{\mathrm{B}}(X, Y)=\xi G^{\mathrm{C}}(X, Y)-(1-\xi) K X+\xi Q Y,
$$

whereas the surplus accruing to target shareholders is given by

$$
G^{\mathrm{T}}(X, Y)=(1-\xi) G^{\mathrm{C}}(X, Y)+(1-\xi) K X-\xi Q Y .
$$

Eq. (4) shows that the gain to the bidding firm reflects the combined takeover surplus as well as the fraction $\xi$ of the target firm that is transferred to bidding shareholders and the fraction $(1-\xi)$ of the bidding firm that is transferred to target shareholders. A similar interpretation applies to (5).

The above characterization shows that the combined takeover surplus and its allocation among participants depend on the size of the bidding and target firms, the synergy parameter $\alpha$, and the relative market valuations of the core businesses of the two firms. The optimality of the decision to enter the takeover deal also depends on other dimensions of the firms' environment such as ongoing uncertainty or the firms' ability to reverse their decisions. Below, we assume that the takeover decision is irreversible. We also assume that firms face two sources of uncertainty.

The first source of uncertainty relates to the cash flows from the core businesses of the two firms. In particular, we assume that the present value of these cash flows is observable and governed by the following stochastic differential equations:

$$
\mathrm{d} A(t)=\mu_{A} A(t) \mathrm{d} t+\sigma_{A} A(t) \mathrm{d} W_{A}(t), \quad A=X, Y,
$$

where $\mu_{A}<r$ and $\sigma_{A}>0$ are constant parameters and $W_{X}$ and $W_{Y}$ are standard Brownian motions on $(\Omega, \mathscr{F}, P)$. This is similar to assuming that cash flows are observable and governed by geometric Brownian motions with starting values $(r-$ $\left.\mu_{X}\right) X(0)$ and $\left(r-\mu_{Y}\right) Y(0)$. These equations imply that the growth rate of core business valuations is normally distributed with mean $\mu_{A} \Delta t$ and variance $\sigma_{A}^{2} \Delta t$ over time interval $\Delta t$. In addition, we presume that the correlation coefficient between the two sources of uncertainty $W_{X}$ and $W_{Y}$ is constant and equal to $\rho$.

(footnote continued)

$$
G^{\mathrm{C}}(X, Y)=(K+Q) \alpha(X-\omega Y) .
$$

This specification (with $\omega$ in front of the bidder valuation $X$ ) has been chosen because it allows us to describe in a simple fashion bidder heterogeneity when we introduce competition for the target. 
The second source of uncertainty relates to the parameter $\omega$ that determines the magnitude of the takeover surplus. As discussed above, we consider that outside investors cannot observe this parameter. However, they can learn about it by observing the behavior of the two firms. We show below that, for each $\omega$, the valuemaximizing policy is to invest when the process $(R(t))_{t \geqslant 0} \equiv(X(t) / Y(t))_{t \geqslant 0}$ first crosses a threshold $R^{*}(\omega)$. At the time of the restructuring, market participants can observe the current value of the process $(R(t))_{t \geqslant 0}$ and infer the value of the parameter $\omega$ using the mapping $\omega \mapsto R^{*}(\omega)$. Before then, the market learns about the value created by the takeover by observing the path of $(R(t))_{t \geqslant 0}$. When the process $(R(t))_{t \geqslant 0}$ reaches a new peak and the firm does not invest, the market revises its beliefs regarding the true value of $\omega$. In addition, unless $\omega=\omega_{\min }$ (where $\omega_{\min }$ is the lowest possible value for $\omega$ ), part of the uncertainty remains unresolved until the announcement of the takeover. Thus, the model generates abnormal returns around takeover announcements.

\section{Mergers with a single bidder}

\subsection{Derivation of the equilibrium}

The analysis in Section 2 indicates that takeovers present participants in the deal with an option to exchange one asset for another - that is they can exchange their shares in the initial firm for a fraction of the shares of the combined firm. Moreover, for any given restructuring policy, the takeover surplus depends on the synergy parameters $\omega$ and $\alpha$ and the relative valuations of the bidding and target firms' core businesses. Because $\omega$ and $\alpha$ are presumed to be constant, the value-maximizing restructuring policy can be characterized by defining a function $\pi(X)$ that represents, for every value of $Y$, a value for $X$ above which the two firms should merge. The value of the option to merge, denoted by $O(X, Y)$, is thus a function of the contemporaneous values of $X$ and $Y$ and the value-maximizing restructuring policy.

The analogy between takeover opportunities and exchange options suggests that the timing of takeover deals is determined by the restructuring strategy that maximizes the value of the exchange option. When analyzing the timing of mergers, however, it is also important to recognize that each participant has the opportunity to enter into the restructuring agreement and has to determine an exercise strategy for its exchange option. This exercise strategy depends on the combined surplus associated with the restructuring and its sharing among participants. Thus, the timing of the restructuring results from a strategic equilibrium in which each firm determines an optimal strategy, while taking into account other firms' exercise strategies.

Consider first the exercise strategy of the bidder. Using standard arguments, it is possible to show that the value of the bidder's restructuring option, denoted by $O^{\mathrm{B}}(X, Y)$, solves the following partial differential equation (see the appendix):

$$
\frac{1}{2} \sigma_{X}^{2} X^{2} O_{X X}^{\mathrm{B}}+\rho \sigma_{X} \sigma_{Y} X Y O_{X Y}^{\mathrm{B}}+\frac{1}{2} \sigma_{Y}^{2} Y^{2} O_{Y Y}^{\mathrm{B}}+\mu_{X} X O_{X}^{\mathrm{B}}+\mu_{Y} Y O_{Y}^{\mathrm{B}}=r O^{\mathrm{B}},
$$


where for any value function $H, H_{x}$ (resp. $H_{x x}$ ) denotes the first-order (resp. secondorder) partial derivative of $H$ with respect to $x$. The right-hand side of Eq. (7) represents the required rate of return on the option to merge. The left-hand side is equal to the expected return on this option due to changes in the values of the state variables $X$ and $Y$.

Eq. (7) is solved subject to the following boundary conditions:

$$
\begin{aligned}
& \left.O^{\mathrm{B}}(X, Y)\right|_{X=\pi^{\mathrm{B}}(Y)}=\left.\xi V(X, Y)\right|_{X=\pi^{\mathrm{B}}(Y)}-K \pi^{\mathrm{B}}(Y), \\
& \left.O_{X}^{\mathrm{B}}(X, Y)\right|_{X=\pi^{\mathrm{B}}(Y)}=\left.\xi V_{X}(X, Y)\right|_{X=\pi^{\mathrm{B}}(Y)}-K, \\
& \left.O_{Y}^{\mathrm{B}}(X, Y)\right|_{X=\pi^{\mathrm{B}}(Y)}=\left.\xi V_{Y}(X, Y)\right|_{X=\pi^{\mathrm{B}}(Y)} .
\end{aligned}
$$

The value-matching (8) imposes an equality between the value of the restructuring option and the payoff of the option upon exercise. Thus, the value of the restructuring option equals, at the time of the takeover, the surplus that bidding shareholders extract from the restructuring. The smooth-pasting conditions (9) and (10) ensure that the restructuring occurs along the optimal path by requiring a continuity of the slopes at the trigger threshold. An additional boundary condition is given by requiring that, as the ratio of the two stock prices decreases, the ratio of the option value to the stock price approaches zero:

$$
\lim _{(X / Y) \rightarrow 0} \frac{O^{\mathrm{B}}(X, Y)}{X}=0 .
$$

Eq. (8) reveals that the payoff of the restructuring option is linear in $X$ and $Y$. Thus, the bidder's exercise strategy can be described using the ratio of these two state variables: $R \equiv X / Y$. In addition, the time-homogeneity of the problem allows us to conclude that the optimal restructuring policy is described by a constant threshold $R^{*}$ at (and above) which it will be optimal to merge. The appendix provides a derivation of the value of the bidder's restructuring option. This value satisfies

$$
O^{\mathrm{B}}(X, Y)=Y[\xi V(R, 1)-K R]\left(\frac{R}{R_{\mathrm{B}}^{*}}\right)^{\beta},
$$

in which the restructuring threshold selected by bidding shareholders is given by

$$
R_{\mathrm{B}}^{*}=\frac{\beta}{\beta-1} \frac{\xi[(K+Q) \alpha-Q]}{\xi[K+\alpha \omega(K+Q)]-K}
$$

and $\beta$ denotes the positive root of the following familiar quadratic equation:

$$
\frac{1}{2}\left(\sigma_{X}^{2}-2 \rho \sigma_{X} \sigma_{Y}+\sigma_{Y}^{2}\right) \beta(\beta-1)+\left(\mu_{X}-\mu_{Y}\right) \beta-r=0 .
$$

Importantly, because $R$ is defined on $\mathbb{R}_{++},(K+Q) \alpha \geqslant Q$ is a necessary condition for bidding shareholders to participate in the deal. In addition, when this condition is satisfied, we have

$$
\frac{\partial R_{\mathrm{B}}^{*}}{\partial \xi}=\frac{-K[(K+Q) \alpha-Q]}{[\xi(K+\alpha \omega(K+Q))-K]^{2}} \leqslant 0 .
$$


This inequality shows that the greater the fraction of the surplus that bidding shareholders extract from the restructuring, the greater are their incentives to participate in the deal. The inequality also highlights an essential difference between the present model and traditional models of takeovers such as Grossman and Hart (1980). In traditional models, the "timing" dimension of the investment decision is typically overlooked and the logical conclusion of the analysis is that it is optimal for target shareholders to hold up the bidder until all the improvement in value is paid to them. In the present model, the timing of the offer depends on the negotiated terms of the offer and hence, when determining these terms, shareholders have to make a tradeoff between a greater surplus later or a lower surplus now.

The exercise strategy of the target can be derived in a similar fashion. The value of the option to merge for the target is given by

$$
O^{\mathrm{T}}(X, Y)=\{Y[(1-\xi) V(R, 1)-Q]\}\left(\frac{R}{R_{\mathrm{T}}^{*}}\right)^{\beta},
$$

in which the restructuring threshold selected by target shareholders satisfies

$$
R_{\mathrm{T}}^{*}=\frac{\beta}{\beta-1} \frac{\xi Q+(1-\xi) \alpha(K+Q)}{(1-\xi)[(K+Q) \alpha \omega+K]} .
$$

The above set of equations can be interpreted as follows. Eqs. (12) and (16) give the value of the option to merge for the bidder and the target, respectively. The first term on the right-hand side of these equations accounts for the surplus associated with the takeover. The second term represents the present value of one dollar contingent on the restructuring. Thus, this second term reflects both the probability that the takeover occurs and the timing of the takeover. Eqs. (13) and (17) give the restructuring thresholds selected by the bidder and the target. The second term on the right-hand side of these equations gives the ratio of the stock prices $R$ above which the restructuring generates a positive surplus (for a given sharing rule for the value of the reorganized firm). Finally, the first term on the right hand side of Eqs. (13) and (17) captures the "option value" associated with uncertainty.

The above developments demonstrate that, for any given sharing rule, each firm can determine the restructuring policy that maximizes the surplus it extracts from the takeover. Given the properties of the combined surplus, the optimal exercise policies take the form of trigger policies described by Eqs. (13) and (17). In equilibrium, the negotiated outcome of the merger satisfies the constraint $R_{\mathrm{B}}^{*}=R_{\mathrm{T}}^{*}$, which determines the allocation of the surplus between firms. We then have the following result.

Proposition 1. The value-maximizing restructuring policy for participating firms is to merge when the ratio of core business valuations $R \equiv X / Y$ reaches the cutoff level

$$
R^{*}=\frac{\beta}{\omega(\beta-1)} .
$$

The share of the combined firm accruing to the bidder is given by

$$
\xi=\frac{K}{K+\omega Q} \text {. }
$$


Proposition 1 highlights several interesting features of merger agreements. First, because the takeover surplus increases with $\omega$, the threshold $R^{*}$ decreases with $\omega$. (The dependency of $R^{*}$ on $\omega$ implies that there is learning in equilibrium.) This in turn implies that the likelihood of a control transaction over a given time interval $[0, T]$ increases with $\omega .{ }^{2}$ Consider, for example, an environment in which $X / Y=2$, the risk-free interest rate is $r=0.1$, the drifts of cash flows from the core business valuations are $\mu_{X}=0.03$ and $\mu_{Y}=0.01$, the correlation coefficient between core business valuations is $\sigma_{X}=\sigma_{Y}=0.2$, and the correlation coefficient between core business valuations $\rho=0.25$. When the synergy of the restructuring increases from $\omega=1$ to 1.25 , the likelihood of a takeover over a five-year period increases from $49.1 \%$ to $86 \%$.

Second, the equilibrium restructuring threshold $R^{*}$ depends on the growth rate and volatility of cash flows from the firms' core businesses as well as the degree of consolidation of the merger (correlation coefficient). In particular, holding their covariance fixed, a greater variance for the changes in $X$ and $Y$ implies more uncertainty over their ratio, and hence an increased incentive to wait. Holding their variances fixed, a greater covariance between the changes in $X$ and $Y$ implies less uncertainty over their ratio, and hence a reduced incentive to wait. These effects are depicted in Fig. 1, which plots the restructuring threshold as a function of the growth rate and volatility of participating firms' core business valuations, and the correlation coefficient between these valuations.

\subsection{Imperfect information and announcement returns}

We now turn to the implications of the model for abnormal announcement returns to stockholders in takeover deals. These returns are equal to the unexpected component of the surplus accruing to shareholders divided by equity value at the time of the takeover. Within the present model, this unexpected component arises because market participants have incomplete information regarding the takeover surplus. However, at the time of the announcement, this uncertainty is resolved by observing the value of the trigger threshold $R^{*}(\omega)$ and the equilibrium allocation of the surplus $\xi$. This is similar in spirit to the analysis in Grenadier (1999) and Lambrecht and Perraudin (2003) where agents infer the private information of other agents through their observed exercise strategies.

To better understand the dynamics of abnormal returns, we can rewrite Eq. (18) as

$$
\omega=\omega\left(R^{*}\right) \equiv \frac{\beta}{R^{*}(\beta-1)} .
$$

\footnotetext{
${ }^{2}$ The probability of takeover over a time interval $[0, T]$ satisfies

$$
P\left(\sup _{0 \leqslant \tau \leqslant t} R(\tau) \geqslant R^{*}\right)=\mathscr{N}\left[\frac{-\ln \left(R^{*} / R_{0}\right)+b T}{\sigma_{R} \sqrt{T}}\right]+\left(\frac{R}{R^{*}}\right)^{\left(2 \mu_{R}-\sigma_{R}^{2}\right) / \sigma_{R}^{2}} \mathscr{N}\left[\frac{-\ln \left(R^{*} / R_{0}\right)-b T}{\sigma_{R} \sqrt{T}}\right],
$$
}

where $b=\left(\mu_{R}-\sigma_{R}^{2} / 2\right) / \sigma_{R}$ and $\mathscr{N}$ is the standard normal cumulative distribution function. 

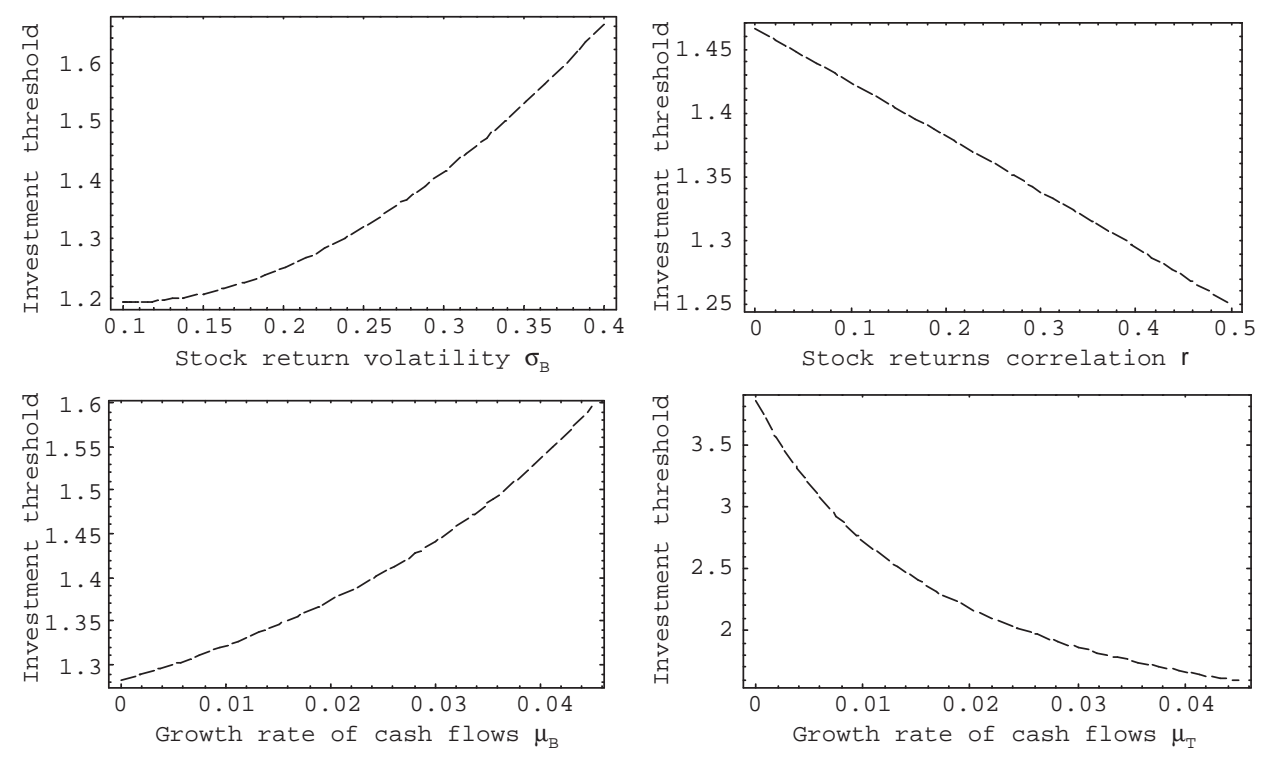

Fig. 1. Restructuring threshold in merger agreements. Plots the selected restructuring threshold in merger agreements as a function of the growth rate and volatility of cash flows from the core businesses of the two firms and the correlation coefficient between changes in these cash flows. Input parameter values are set as in the base case environment.

This equation indicates that there exists a negative, monotonic relation between the restructuring point and the identified synergy. Thus, by observing the behavior of the two firms - and in particular whether the two firms exercise their option when $R$ reaches a new peak - the market can update its beliefs regarding the value of $\omega$.

To determine the implications of the model for abnormal returns, we assume that the prior distribution of $\omega$ is uniform with sample space $\left\{1-\sigma_{\omega}, 1,1+\sigma_{\omega}\right\}$ so that each outcome can occur with equal probability. This assumption implies that its posterior distribution at any time $t$ is also uniform. Denote by $\tau$ the time of the takeover announcement and assume that $\omega=1$. Just before the takeover announcement, we have

$$
\sup _{s \leqslant \tau} R_{s}>R^{*}\left(1+\sigma_{\omega}\right)=\frac{\beta}{\left(1+\sigma_{\omega}\right)(\beta-1)}
$$

(so that investors know that $\omega \neq 1+\sigma_{\omega}$ ) and we can write the value of the bidding firm as (using $Y$ as numéraire)

$$
B\left(\tau_{-}\right)=K R\left(\tau_{-}\right)+\frac{1}{2}\left[O^{\mathrm{B}}\left(R\left(\tau_{-}\right), 1 ; 1\right)+O^{\mathrm{B}}\left(R\left(\tau_{-}\right), 1 ; 1-\sigma_{\omega}\right)\right],
$$

where $O^{\mathrm{B}}(R, 1 ; x)$ is the value of the bidder's option to merge conditional on $\omega=x$. The first term on the right-hand side of Eq. (21) represents the value of the bidding firm core business. The second term reflects the potential gain associated with a takeover for bidding shareholders. 
By definition, since $O^{\mathrm{B}}(X, Y ; \omega)$ increases with $\omega$, we have

$$
\left[\xi V\left(R^{*}, 1\right)-K R^{*}\right] \geqslant \frac{1}{2}\left[O^{\mathrm{B}}\left(R^{*}, 1 ; 1\right)+O^{\mathrm{B}}\left(R^{*}, 1 ; 1-\sigma_{\omega}\right)\right],
$$

for all $t \leqslant \tau$, where $R^{*}$ is defined in Proposition 1 . This inequality implies positive abnormal announcement stock returns to bidding shareholders in the basic model. In particular, these abnormal announcement returns satisfy

$$
A R(\tau)=\frac{\frac{1}{2}\left[O^{\mathrm{B}}\left(R^{*}, 1 ; 1\right)-O^{\mathrm{B}}\left(R^{*}, 1 ; 1-\sigma_{\omega}\right)\right]}{B\left(\tau_{-}\right)} .
$$

Fig. 2 plots abnormal announcement returns as a function of the growth rate and volatility of the participating firms' cash flows and the degree of consolidation of the merger (correlation coefficient). In the figure, the solid line represents abnormal
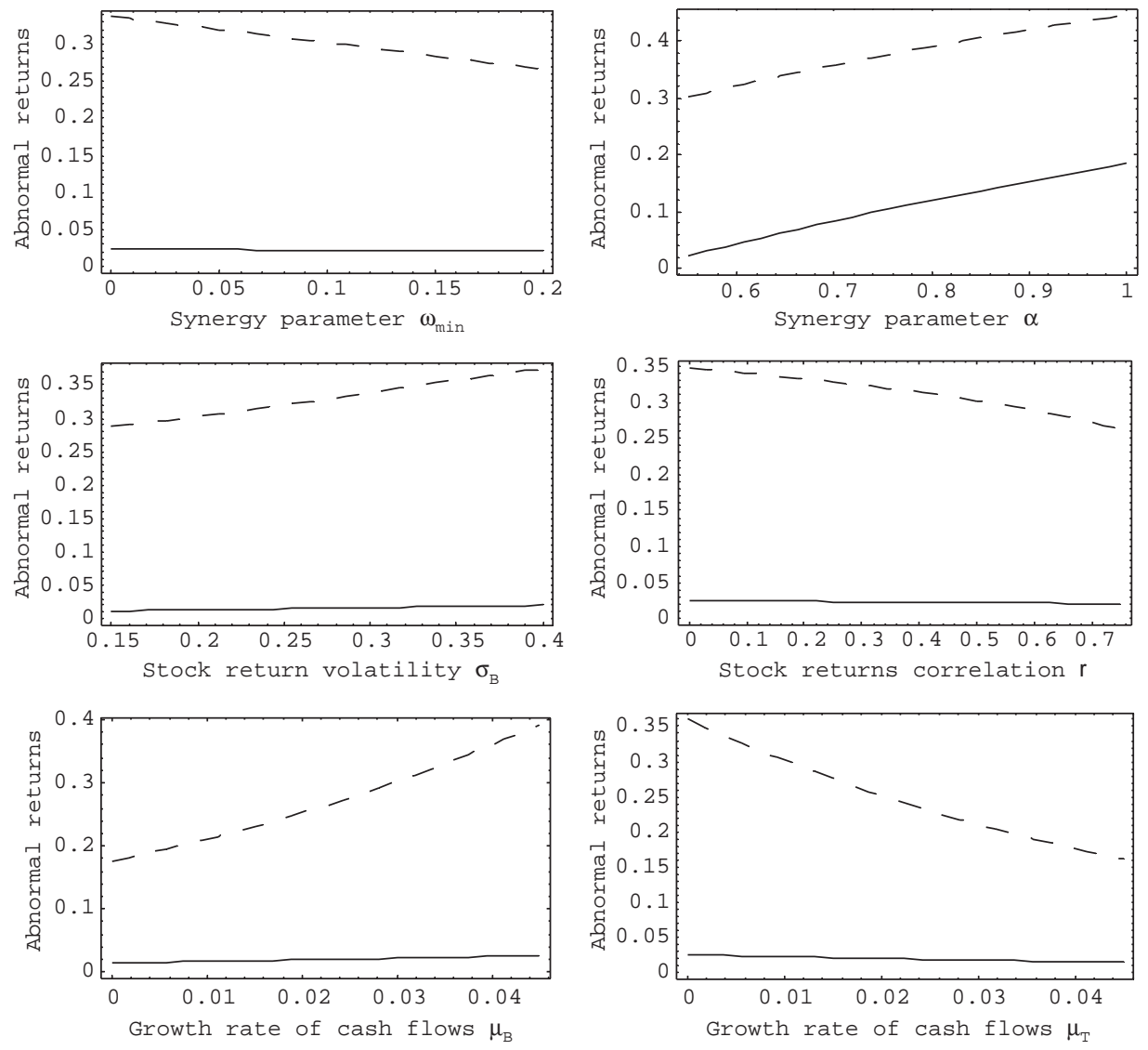

Fig. 2. Abnormal returns in merger announcements. Plots abnormal returns to shareholders in merger agreements as a function of the growth rate and volatility of cash flows from the core businesses of the two firms and the correlation coefficient between changes in these cash flows. Input parameter values are set as in the base case environment. In this figure, the solid line represents returns to bidding shareholders, and the dashed line represents returns to target shareholders. 
returns to bidding shareholders and the dashed line represents abnormal returns to target shareholders.

Because the timing of the merger depends on the growth rate and volatility of the firms' core business valuations and the degree of consolidation of the merger, abnormal returns to shareholders depend on these factors as well. In particular, the model predicts that returns to bidding and target shareholders should (1) decrease with the degree of consolidation of the merger and the growth rate of the target's core business valuation and (2) increase with volatility and the growth rate of the bidder's core business valuation. These effects are depicted in Fig. 2, which also shows that abnormal returns to target shareholders typically exceed abnormal returns to bidding shareholders (the appendix shows that it is always the case when the bidding firm is larger than the target or $K \geqslant Q$ ). Finally, it should be noted that without competition, returns to bidding shareholders are always positive, which is inconsistent with the available evidence. We show below that competition and imperfect information can generate negative abnormal announcement returns, even when agents have rational expectations.

\subsection{Central-planning formulation}

One interesting feature of the equilibrium described in Proposition 1 is that it can be formulated as a surplus-maximization problem for a central planner. The objective of the planner is to determine the restructuring policy that maximizes the combined surplus

$$
G^{\mathrm{C}}(X, Y)=(K+Q) \alpha(\omega X-Y) .
$$

Using similar arguments as above, it is possible to show that the surplus-maximizing policy is identical to the restructuring policy described in Proposition 1 (see the appendix). Thus, the restructuring policy associated with the merger coincides with the one that would be chosen by a surplus-maximizing planner. This suggests that the equilibrium described in Proposition 1 can be derived by first determining a sharing rule for the takeover surplus and then selecting the timing that maximizes this surplus. The only renegotiation-proof allocation under that scenario is the one described in Proposition 1.

\section{Introducing competition}

\subsection{Competition and the timing of takeovers}

In this section, we extend the analysis by considering that two potential acquirers that differ in terms of synergy benefit $\omega$ can compete for the target. (In the appendix, we examine the timing of takeovers when firms differ in terms of $\alpha$ and $\omega$. .) Introducing competition among multiple bidders impacts the mechanism determining the equilibrium timing and terms of the takeover. One essential difference from the case of a single bidder is the decay in the bidders' bargaining power due to 
competition. Competition among bidders puts the target in an advantageous position and allows target shareholders to extract a higher premium from the bidding firms.

To determine the timing and terms of the takeover, we first examine the optimization problem of bidding shareholders. Once the takeover contest is initiated, both bidders submit their bids to the target in the form of the fraction of the new firm's equity to be owned by target shareholders upon the takeover consumation. The maximum value of that fraction, or the maximum price that a bidder is willing to pay to acquire the target, makes the bidder indifferent between winning and losing the takeover contest. The bidder never places a bid in excess of that value, since it would be better to lose the contest and let the other bidder acquire the target. Denote by $K_{i}$ the size of bidder $i$ and assume that both bidders belong to the same industry so that their cash flows are driven by the same process $X{ }^{3}$ Then the breakeven stake of bidder $i$ is the solution to

$$
\xi_{b e i} V\left(X, Y ; \omega_{i}\right)-K_{i} X=0 \Longleftrightarrow \xi_{b e i}=\frac{K_{i} X}{V\left(X, Y ; \omega_{i}\right)}, \quad i=1,2 .
$$

Assume that we adopt a Nash equilibrium and denote by $\xi_{i}$ the ownership share that bidder $i$ would obtain if it were the only bidder. Then the reaction function of bidder 1 can be defined as follows:

1. Suppose that $V\left(X, Y ; \omega_{1}\right)>V\left(X, Y ; \omega_{2}\right)$. Then bidder 1 is the stronger of the two and wins the takeover contest. Depending on the current value of the ratio of the stochastic processes $R=X / Y$ and the asymmetry between the synergy parameters $\omega_{1}$ and $\omega_{2}$, two different scenarios are possible:

(a) The value associated with the equilibrium share offered to target shareholders is greater than the breakeven value of the weaker bidder:

$$
\left(1-\xi_{b e 2}\right) V\left(X, Y ; \omega_{2}\right)<\left(1-\xi_{1}\right) V\left(X, Y ; \omega_{1}\right),
$$

where $\xi_{1}$ can be obtained by solving (13) for $\xi_{1}$ :

$$
\xi_{1}=\frac{K_{1} R}{R\left(K_{1}+\alpha \omega_{1}\left(K_{1}+Q\right)\right)-[\beta /(\beta-1)]\left(\alpha\left(K_{1}+Q\right)-Q\right)} .
$$

In this case bidder 2 is too weak to matter, as it drops out of takeover contests at bid values below that of the equilibrium bid of the stronger bidder. Therefore, the equilibrium terms of the takeover will be the same as in the case of a single bidder.

(b) The value associated with the equilibrium share offered to target shareholders is lower than the breakeven value of the weaker bidder:

$$
\left(1-\xi_{b e 2}\right) V\left(X, Y ; \omega_{2}\right)>\left(1-\xi_{1}\right) V\left(X, Y ; \omega_{1}\right) .
$$

\footnotetext{
${ }^{3}$ Extending the model to incorporate a third stochastic process (one for the target and one for each bidder) would not add many new economic insights. Indeed, we already capture heterogeneity by using a correlation coefficient that is less than one between $X$ and $Y$. Moreover, most of the results in this section do not rely on the specific dynamics of the stochastic processes governing cash flows from assets in place so that having one or two processes would not change anything.
} 
Now bidder 1 can no longer ignore the presence of bidder 2. If bidder 1 offers its equilibrium stake to target shareholders, just as in the case with no competition, then bidder 2 has an incentive to outbid, as it will be better off by winning the contest. This incentive disappears once the bid value reaches the breakeven threshold of bidder 2. Therefore, bidder 1 has to keep an ownership stake in the combined firm such that the value to the target of dealing with bidder 1 is not less than that of dealing with bidder 2. Denote this stake by $\xi_{1 \max }$. Then bidder 1 has no incentive to keep a stake that is lower than $\xi_{1 \max }$ by any material amount. By offering $1-\xi_{1 \max }+\varepsilon$ bidder 1 is able to ward off competition, since any bid in excess of $1-\xi_{1 \max }$ makes bidder 2 strictly better off by dropping out of the auction. Since $\varepsilon$ can be made arbitrarily small, we do not take it into consideration and the equilibrium share of the bidder is $\xi_{1 \max }$.

2. Suppose that $V\left(X, Y ; \omega_{2}\right)>V\left(X, Y ; \omega_{1}\right)$. Then bidder 2 is the stronger of the two and wins the takeover contest. As above, two different scenarios are possible depending on the current value of the ratio of the stochastic processes $R=X / Y$ and the asymmetry between bidder characteristics.

Suppose that $V\left(X, Y ; \omega_{i}\right)>V\left(X, Y ; \omega_{j}\right)$. The above argument implies that when there is competition, the winning bidder requires an ownership fraction that is no higher (and possibly lower) than in the absence of competition. Thus, the downwardsloping reaction function $R\left(\min \left(\xi_{i}, \xi_{i \max }\right)\right)$ coincides (case a) or lies below (case b) the reaction function under no competition. It follows that the intersection with the target's upward-sloping reaction function $R_{\mathrm{T}}(\xi)$ shifts to the left along the target's reaction function, i.e., it occurs at a threshold value of $R$ not higher (and possibly lower) than in the case with one bidder. Denote by $R_{b e j}$ the ratio of core business valuations for which the breakeven share of the losing bidder (bidder $j$ ) is equal to the equilibrium share of the target. This ratio solves the nonlinear equation

$$
\xi_{\text {imax }}=\frac{(\beta-1) R\left[(K+Q) \alpha \omega_{i}+K\right]-\beta \alpha(K+Q)}{(\beta-1) R\left[(K+Q) \alpha \omega_{i}+K\right]+\beta[Q-\alpha(K+Q)]},
$$

where the right-hand side of this equation has been obtained by solving (17) for $\xi_{\mathrm{T}}$. We then have the following result. ${ }^{4}$

Proposition 2. Competition for the target firm speeds up the takeover process and erodes the ownership stake of bidding shareholders. When there is competition and $V\left(X, Y ; \omega_{i}\right)>V\left(X, Y ; \omega_{j}\right)$, the takeover takes place the first time the ratio of core business valuations $\left(R_{t}\right)_{t \geqslant 0}=\left(X_{t} / Y_{t}\right)_{t \geqslant 0}$ reaches the threshold $R^{*}$ defined by

$$
R^{*}=\min \left[R_{i}, R_{b e j}\right],
$$

where $R^{*}=R_{i}$ defined in (18) when the losing bidder is weak and $R^{*}=R_{b e j}$ defined in (25) when the losing bidder is strong. Moreover, the share of the combined firm

\footnotetext{
${ }^{4}$ In the appendix we show that when $\alpha_{1} \neq \alpha_{2}$, there exists a critical point $\bar{R}$ such that if $R<(>) \bar{R}$ then bidder 2 (1) is stronger. Consequently, the value of $R$ at the start of the game determines which bidder wins the takeover. We thank the referee for suggesting this point to us.
} 
accruing to the bidder is given by

$$
\xi=\min \left[\frac{K R^{*}+(K+Q) \alpha\left(\omega_{i}-\omega_{j}\right) R^{*}}{V\left(R^{*}, 1 ; \omega_{i}\right)}, \frac{K}{K+\omega_{i} Q}\right],
$$

where the min function takes a value equal to its first argument when competition erodes the ownership share of bidding shareholders and a value equal to its second argument otherwise.

Fig. 3 illustrates this result by providing the reaction functions of the bidder and the target for different parameter values. The dashed line represents the reaction function of bidder 1 if there is no competition and the dotted line represents the share in the combined entity corresponding to the breakeven value of the second bidder. The reaction function of the target is provided by the solid line. In this figure we presume that $\omega_{1}=1$. In addition, we have $\omega_{2}=0.6$ in $3 \mathrm{a}$ (weak second bidder) and $\omega_{2}=0.95$ in $3 b$ (strong second bidder).
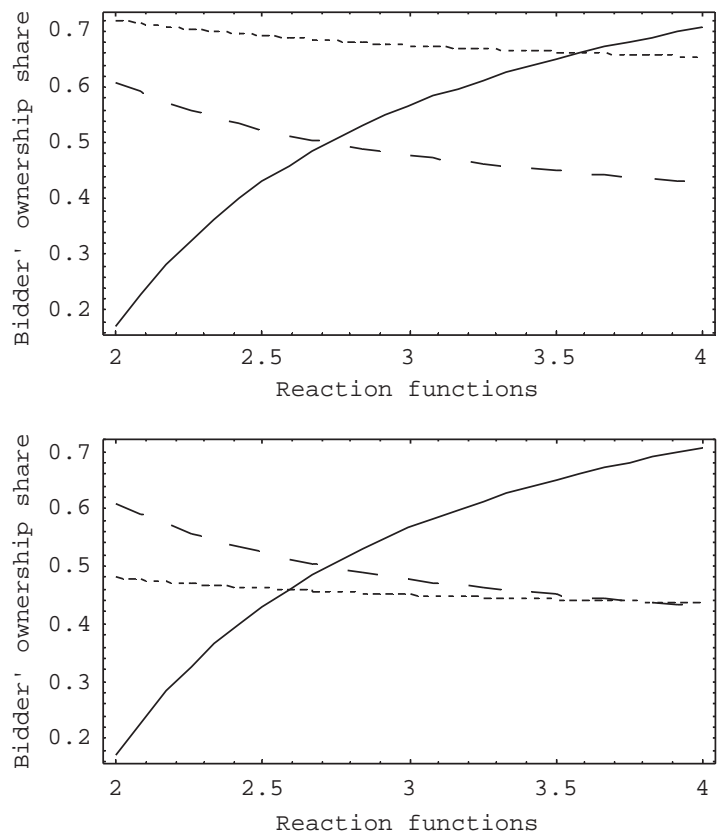

Fig. 3. Reaction function of bidding and target shareholders. Plots the reaction function of bidding and target shareholders when there is competition among bidders. Input parameter values are set as in the base case. The dashed line represents the reaction function of bidder 1 if there is no competition while the dotted line represents the share in the combined entity corresponding to the breakeven value of the second bidder. The reaction function of the target is provided by the solid line. In this figure we presume that $\omega_{1}=1$. In addition, we have $\omega_{2}=0.6$ in (a) (weak second bidder) and $\omega_{2}=0.95$ in (b) (strong second bidder). 
Consistent with the above arguments, when the second bidder is weak (as in Fig. 3a), the equilibrium is unaffected by competition. However, when the second bidder is sufficiently strong (Fig. 3b), the winning bidder has to pay the value of the breakeven share of bidder 2. This shifts its reaction curve downwards and speeds up the takeover. For example, in Fig. $3 b$ the takeover threshold drops from 2.72 to 2.45 and the probability of takeover over a five-year horizon increases from $49.1 \%$ to $65 \%$. When the two bidders are identical, their breakeven values coincide and target shareholders are able to extract the whole takeover surplus. In this case, the takeover is always accelerated, since for any given $R$, the winning bidder has to offer a higher share to the target than it would absent competition.

\subsection{Competition and announcement returns}

As in Section 3, abnormal announcement returns are equal to the unexpected component of the surplus accruing to shareholders divided by equity value at the time of the takeover. When there is competition for the target, this unexpected component arises for two reasons. First, market participants have incomplete information regarding the takeover surplus. Second, in the case of multiple bidders, market participants typically cannot identify the winning bidder before the takeover announcement. Therefore, at any date outside investors determine each bidder's probability of winning. These probabilities are updated as new information arrives. At the time of the takeover announcement, uncertainty is partially (or totally) resolved by observing the value of the trigger threshold $R^{*}(\omega)$ and the equilibrium bid.

To characterize abnormal returns in a simple fashion, we consider that $K_{1}=$ $K_{2}=K$ and $\alpha_{1}=\alpha_{2}=\alpha$. In addition, we presume that the prior beliefs of outside investors are that the $\omega_{i}$ are independent and uniformly distributed on $\left\{\omega_{i \min }, \omega_{i \mathrm{av}}, \omega_{i \max }\right\}, i=1,2 .^{5}$ As outside investors observe the investment behavior of participating firms, they update their beliefs regarding the possible values of the $\omega_{i}$. At the time of the takeover, abnormal returns to shareholders typically depend on the remaining uncertainty. Three cases are possible.

1. $\omega_{2 \max }<\omega_{1 \mathrm{~min}}$. In this case, outside investors know at the beginning that the target will merge with bidder 1 . However, the value of bidder 1's option to merge and the equilibrium takeover surplus are uncertain. Abnormal announcement returns to bidder 1 can be either positive or negative, depending on the dispersion of beliefs regarding the synergy value created in the takeover.

2. $\omega_{2 \max }>\omega_{1 \min }$ and $\min \left(\xi_{1}, \xi_{1 \max }\right)=\xi_{1}$. In this case, the outcome of the takeover contest is not known initially. By observing the behavior of the firms before the

\footnotetext{
${ }^{5}$ When $\omega$ is drawn from a probability distribution $F(\omega)$ with continuous probability density function $f(\omega)$, outside investors update their beliefs about the distribution as follows:

$$
f\left(\omega \mid R^{\sup }(t)\right)=\frac{f(\omega)}{1-f\left(\omega\left(R^{\sup }(t)\right)\right)} \quad \text { and } \quad F\left(\omega \mid R^{\sup }(t)\right)=\frac{F(\omega)-F\left(\omega\left(R^{\sup }(t)\right)\right)}{1-F\left(\omega\left(R^{\sup }(t)\right)\right)},
$$

where $R^{\text {sup }}(t) \equiv \sup _{0 \leqslant s \leqslant t} R(s)$ and $\omega\left(R^{\text {sup }}(t)\right) \equiv I\left[R^{*}(\omega) \mid R^{*}(\omega)=R^{\text {sup }}(t)\right]$, where $I($.$) inverts R^{*}(\omega)$, meaning that $I\left[R^{*}(\omega)\right]=\omega$ for all $\omega$. Assuming a "prior" support $\left[\omega_{\min }, \omega_{\max }\right]$ for $\omega$, the "posterior" support of beliefs is given at any time $t$ by $\left[\omega_{\min }, \min \left(\omega_{\max }, \omega\left(R^{\text {sup }}(t)\right)\right)\right]$.
} 
takeover, investors may be able to infer the identity of the winning bidder. At the time of the takeover, investors learn both that bidder 1 is the winning bidder and the value of the synergy parameter $\omega_{1}$. Again, abnormal announcement returns to bidder 1 can be either positive or negative.

3. $\omega_{2 \max }>\omega_{1 \min }$ and $\min \left(\xi_{1}, \xi_{1 \max }\right)=\xi_{1 \max }$. This case is similar to case 2 except that bidder 1 offers a stake corresponding to the breakeven value of bidder 2 .

As in the case of a single bidder, we denote by $\tau$ the time of the takeover announcement. The expected value of the bidder before the announcement is

$$
B_{1}\left(\tau_{-}\right)=X K+E_{\tau_{-}}\left[1_{\omega_{1}>\omega_{2}} O^{\mathrm{B}}\left(X, Y ; \omega_{1}\right)\right] .
$$

The first term on the right-hand side of this equation is the value of the bidder's core business. The second term represents the expected present value of the takeover surplus. Since we assume a finite set of possible realizations for the pairs $\left(\omega_{1}, \omega_{2}\right)$ and different pairs generally result in different takeover thresholds, investors learn the values of both $\omega_{1}$ and $\omega_{2}$ by observing the takeover threshold. Therefore, $E\left(\omega_{1} \mid \xi_{1 \max }\right)=\omega_{1}$ and the value of the share of bidder 1's shareholders just after the takeover announcement becomes

$$
B_{1}(\tau)=X\left[K+\alpha\left(\omega_{1}-\omega_{2}\right)(K+Q)\right] .
$$

Abnormal returns to bidding shareholders at the time of the takeover announcement are then defined as: $A R_{\mathrm{B}}(\tau)=\left(B(\tau)-B\left(\tau_{-}\right)\right) / B\left(\tau_{-}\right)$.

Using Eqs. (26) and (27), we see that takeover deals can entail either positive or negative returns to bidder 1 . The sign of the returns depends on the difference in true synergy parameters. For example, if the two bidders are identical, uncertainty in market beliefs always generates negative abnormal returns around announcements. Indeed, in this case a bidder's option to merge is worthless in (27). However, the market's expectation of this option is positive in (26). In general, when the difference in synergy parameters is small, so is the premium that accrues to bidder 1 at the time of the takeover. If the uncertainty in market beliefs is high (high $\omega_{2 \max }-\omega_{2 \min }$ ), then the market's (conditional) expectation of the merger benefits might exceed its true value. Therefore, the market overestimates the benefits of the merger to bidder 1 and we observe negative abnormal returns to bidder 1 at the takeover announcement. ${ }^{6}$ If the difference between $\omega_{1}$ and $\omega_{2}$ is large, then the true value

\footnotetext{
${ }^{6}$ For example, assume that $\sigma_{1}=0, \sigma_{2}>0$, and $\omega_{2}-\sigma_{2}<\omega_{2}<\omega_{1}<\omega_{2}+\sigma_{2}$. If by the time of the takeover the pair $\left(\omega_{1}, \omega_{2}+\sigma_{2}\right)$ is ruled out, then the value of the bidding firm before the takeover announcement is

$$
B\left(\tau_{-}\right)=K R\left(\tau_{-}\right)+\frac{1}{2}\left[O^{\mathrm{B}}\left(R\left(\tau_{-}\right), \omega_{1}, \omega_{2}\right)+O^{\mathrm{B}}\left(R\left(\tau_{-}\right), \omega_{1}, \omega_{2}-\sigma_{2}\right)\right] .
$$

This implies that abnormal returns satisfy

$$
A R(\tau)=\frac{\frac{1}{2}\left[O^{\mathrm{B}}\left(R^{*}, \omega_{1}, \omega_{2}\right)-O^{\mathrm{B}}\left(R^{*}, \omega_{1}, \omega_{2}-\sigma_{2}\right)\right]}{B\left(\tau_{-}\right)}<0
$$

since the winning bidder pays the breakeven value corresponding to $\omega_{2}$, which is higher than the one corresponding to $\omega_{2}-\sigma_{2}$.
} 

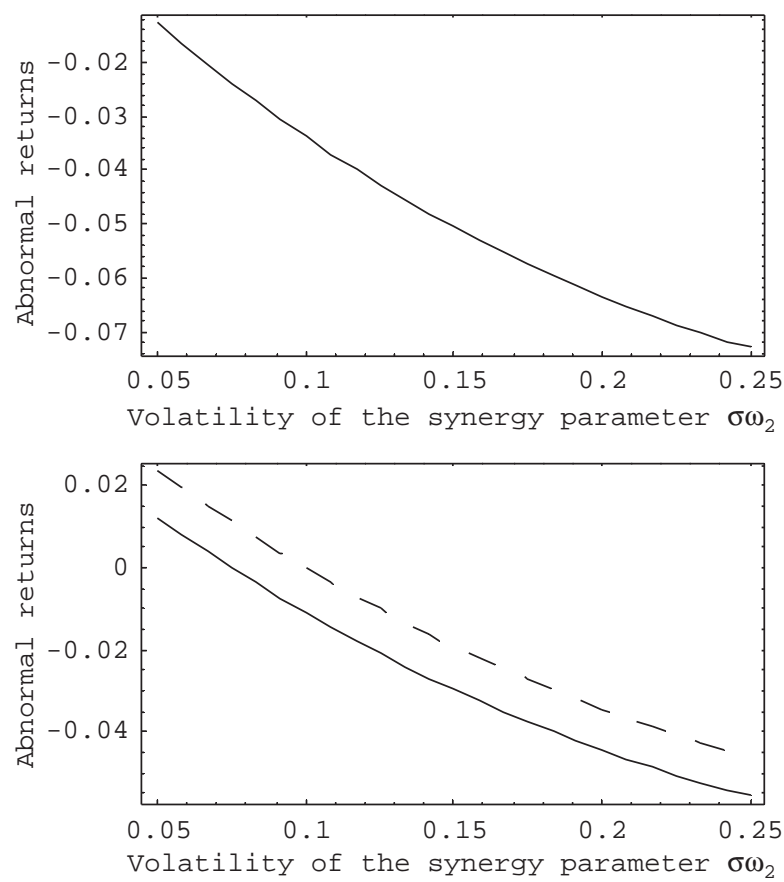

Fig. 4. Abnormal announcement returns to bidding shareholders. Plots abnormal announcement returns to the winning bidder as a function of the dispersion of beliefs about the synergy parameter of bidder 2 , $\sigma_{\omega_{2}}$, for the standard set of input parameters. The synergy parameter of the stronger bidder is set equal to $\omega_{1}=1$ and its volatility is set equal to $\sigma_{\omega_{2}}=0.1$. The synergy parameter of the weaker bidder is given by $\omega_{2}=1$ in (a) so that abnormal returns are always negative. The synergy parameter of the weaker bidder is given by $\omega_{2}=0.95$ (solid line) or $\omega_{2}=0.9$ (dashed line) in (b) so that abnormal returns can be either positive (low dispersion of beliefs) or negative (high dispersion of beliefs).

of bidder 1's option to merge is higher than its expectation. In that case, abnormal announcement returns to bidding shareholders are positive.

The model, therefore, predicts that with competition and imperfect information, the sign (and the magnitude) of the abnormal returns to the winner of the takeover contest depends on the degree of asymmetry between bidders. Low asymmetry implies negative returns; high asymmetry implies positive returns. Obviously, abnormal announcement returns also depend on the magnitude of uncertainty related to synergy parameters. Let $\sigma_{\omega 2}$ be a measure of the dispersion of investors' beliefs about the synergy gain of bidder 2 so that $\omega_{2 \min }=\omega_{2}-\sigma_{\omega 2}$ and $\omega_{2 \max }=\omega_{2}+\sigma_{\omega 2}$. Fig. 4 plots abnormal announcement returns to bidding shareholders as a function of $\sigma_{\omega 2}$ for different values of $\omega_{1}$ and $\omega_{2}$.

Consistent with the above discussion, Fig. 4 a reveals that when the two bidders are identical, abnormal returns to bidder 1 are always negative. In this case the bidders compete all the rents associated with the merger away. Moreover, high uncertainty in beliefs about bidder $2, \sigma_{\omega 2}$, leads to a high magnitude of abnormal returns to bidder 1. Fig. $4 \mathrm{~b}$ illustrates the following two additional points. First, as the magnitude of 
the asymmetry between the bidders increases, abnormal announcement returns increase and can become positive (for lower values of $\sigma_{\omega 2}$ ). In addition, these abnormal returns decrease with the dispersion of beliefs regarding the synergy parameter of the weaker bidder and can become again negative as $\sigma_{\omega 2}$ becomes larger.

Consider next the returns to target shareholders. When the second bidder is too weak to matter, the timing and terms of the takeover are not affected by competition. As a result, abnormal returns to target shareholders are similar to those derived in Section 3. When competition erodes the bargaining power of bidding shareholders, the terms of the takeover to target shareholders are improved. As a result, their returns remain positive and larger than the abnormal returns to bidding shareholders. Moreover, and as in the case of the single bidder, the reaction function of the target in Fig. 3 increases with the degree of consolidation of the merger and the growth rate of the target's core business valuation and decreases with volatility and the growth rate of the bidder's core business valuation. In the case of the weak second bidder, this effect is augmented by a shift in the opposite direction of the equilibrium reaction function $\xi_{1}$ of bidding shareholders. As a result, abnormal returns to target shareholders should (1) decrease with the degree of consolidation of the merger and the growth rate of the target's core business valuation and (2) increase with volatility and the growth rate of the bidder's core business valuation (Fig. 5).

These results are consistent with empirical evidence reported by Schwert (2000) and Andrade et al. (2001) that returns to target shareholders around the takeover announcement typically are positive whereas returns to bidding shareholders
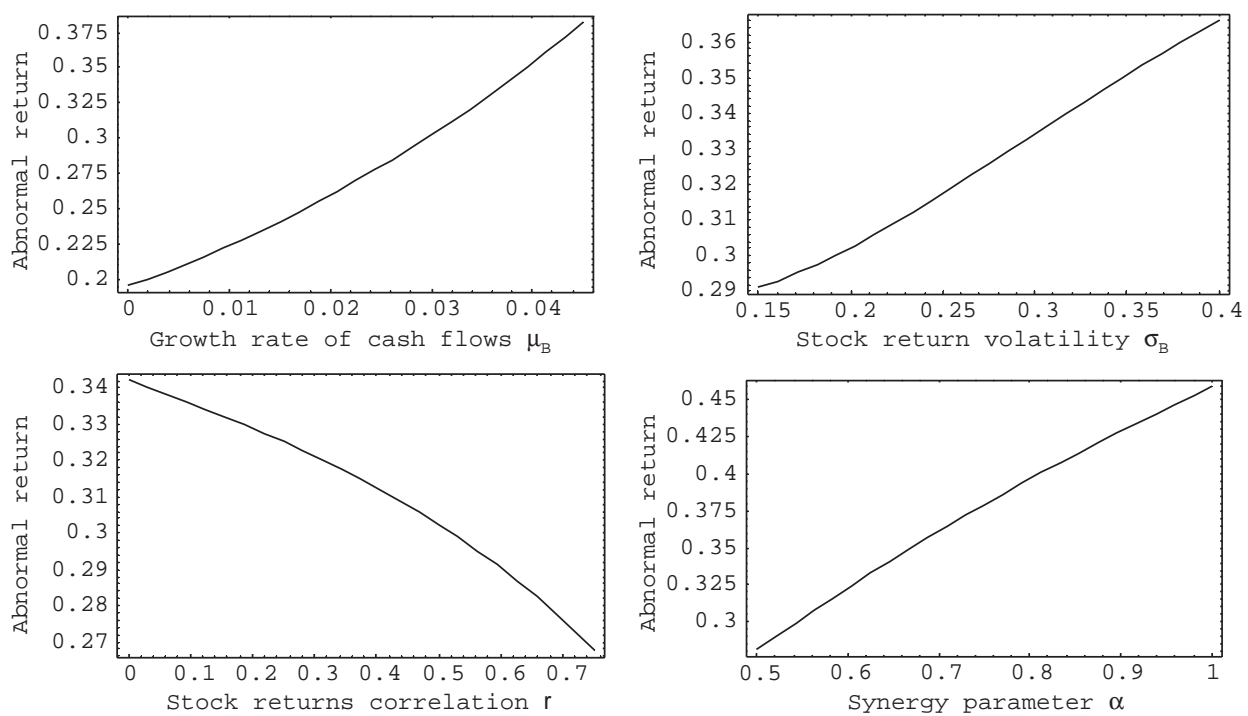

Fig. 5. Abnormal returns to target shareholders around merger announcements. Plots abnormal returns to target shareholders around merger announcements when the synergy parameter of the stronger bidder is set equal to $\omega_{1}=1$ and its volatility is set equal to $\sigma_{\omega_{1}}=0.1$. The synergy parameter of the weaker bidder is given by $\omega_{2}=0.95$ and its volatility is set equal to $\sigma_{\omega_{2}}=0.2$, so that abnormal returns to bidding shareholders are negative. 
typically are negative. Interestingly, the present model can generate returns that are consistent with the empirical evidence even though agents have rational expectations. In particular, the analysis reveals that negative announcement returns to bidding shareholders can arise simply because of the difficulty of estimating the potential synergies generated by the control transaction. We show that if beliefs are sufficiently dispersed and the two potential bidders have similar characteristics, returns will be negative. The additional implications of the model regarding abnormal announcement returns are novel and provide further opportunity for empirical research.

\section{Conclusion}

This paper develops a dynamic model of takeovers that jointly determines the timing and the terms of takeovers. The model makes an analogy between restructuring opportunities and exchange options. The analysis in the paper also recognizes the role of the strategic interaction between participants to the deal and derives equilibrium restructuring strategies by solving option exercise games between bidding and target shareholders. The model incorporates imperfect information, learning, and competition and shows how all three elements interact to determine abnormal returns to stockholders around takeover announcements.

The returns associated with the equilibrium restructuring strategies derived in the paper are consistent with empirical evidence. Specifically, the model predicts that (1) returns to target shareholders should be larger than returns to bidding shareholders, (2) returns to bidding shareholders can be negative if there is competition for the acquisition of the target and uncertainty regarding the synergy of the takeover, and (3) competition among heterogeneous firms affects returns in takeover deals and speeds up the acquisition process. In addition, the paper generates new predictions relating abnormal returns to bidding and target shareholders to the drift, volatility, and correlation coefficient of the bidder and target stock returns.

\section{Appendix A. Timing and terms of the merger}

Denote the value of the bidder's restructuring option by $O^{\mathrm{B}}(X, Y)$. In the region for the two state variables where there is no takeover, the instantaneous change in the value of the option to merge satisfies (by an application of Itô's lemma)

$$
\mathrm{d} O^{\mathrm{B}}=\mathrm{d} X O_{X}^{\mathrm{B}}+\mathrm{d} Y O_{Y}^{\mathrm{B}}+\left[\frac{1}{2} \sigma_{X}^{2} X^{2} O_{X X}^{\mathrm{B}}+\rho \sigma_{X} \sigma_{Y} X Y O_{X Y}^{\mathrm{B}}+\frac{1}{2} \sigma_{Y}^{2} Y^{2} O_{Y Y}^{\mathrm{B}}\right] \mathrm{d} t .
$$

The equilibrium expected return on the restructuring option is $r$. Combining this equilibrium condition with Eq. (A.1) gives the partial differential equation

$$
r O^{\mathrm{B}}=\mu_{X} X O_{X}^{\mathrm{B}}+\mu_{Y} Y O_{Y}^{\mathrm{B}}+\frac{1}{2} \sigma_{X X}^{2} X^{2} O_{X X}^{\mathrm{B}}+\rho \sigma_{X} \sigma_{Y} X Y O_{X Y}^{\mathrm{B}}+\frac{1}{2} \sigma_{Y}^{2} Y^{2} O_{Y Y}^{\mathrm{B}},
$$


which is solved subject to the value-matching and smooth-pasting conditions

$$
\begin{aligned}
& \left.O^{\mathrm{B}}(X, Y)\right|_{X=\pi^{\mathrm{B}}(Y)}=\left.\xi V(X, Y)\right|_{X=\pi^{\mathrm{B}}(Y)}-K \pi^{\mathrm{B}}(Y), \\
& \left.O_{X}^{\mathrm{B}}(X, Y)\right|_{X=\pi^{\mathrm{B}}(Y)}=\left.\xi V_{X}(X, Y)\right|_{X=\pi^{\mathrm{B}}(Y)}-K, \\
& \left.O_{Y}^{\mathrm{B}}(X, Y)\right|_{X=\pi^{\mathrm{B}}(Y)}=\left.\xi V_{Y}(X, Y)\right|_{X=\pi^{\mathrm{B}}(Y)},
\end{aligned}
$$

and the boundary condition

$$
\lim _{(X / Y) \rightarrow 0} \frac{O^{\mathrm{B}}(X, Y)}{X}=0 .
$$

The value function $O^{\mathrm{B}}(X, Y)$ is linearly homogeneous in $X$ and $Y$. Thus, the optimal restructuring policy can be described using the ratio of the two stock prices: $R=X / Y$. Also, the value of the restructuring option can be written as

$$
O^{\mathrm{B}}(X, Y)=Y O^{\mathrm{B}}(X / Y, 1)=Y O^{\mathrm{B}}(R) .
$$

Successive differentiation gives

$$
\begin{aligned}
& O_{X}^{\mathrm{B}}(X, Y)=O_{R}^{\mathrm{B}}(R), \\
& O_{Y}^{\mathrm{B}}(X, Y)=O^{\mathrm{B}}(R)-R O_{R}^{\mathrm{B}}(R), \\
& O_{X X}^{\mathrm{B}}(X, Y)=O_{R}^{\mathrm{B}}(R) / Y, \\
& O_{X Y}^{\mathrm{B}}(X, Y)=-R O_{R R}^{\mathrm{B}}(R) / Y, \\
& O_{Y Y}^{\mathrm{B}}(X, Y)=R^{2} O_{R R}^{\mathrm{B}}(R) / Y .
\end{aligned}
$$

Substituting (A.7)-(A.12) in the partial differential (A.2) and boundary (A.3)-(A.6) yields the ordinary differential equation (using $Y$ as numéraire)

$$
\frac{1}{2} \sigma_{R}^{2} R^{2} O_{R R}^{\mathrm{B}}+\mu_{R} R O_{R}^{\mathrm{B}}=\left(r-\mu_{Y}\right) O^{\mathrm{B}}
$$

with the value-matching and smooth-pasting conditions

$$
\begin{aligned}
& O\left(R^{*}\right)=\xi V(R, 1)-K R, \\
& O_{R}\left(R^{*}\right)=\xi V_{R}(R, 1)-K,
\end{aligned}
$$

as well as the no-bubbles condition

$$
\lim _{R \rightarrow 0} O^{\mathrm{B}}(R)=0 .
$$

The general solution to Eq. (A.14) is given by

$$
O^{\mathrm{B}}(R)=A R^{\beta}+B R^{\gamma},
$$

where $A$ and $B$ are positive constants and $\beta$ and $\gamma$ are, respectively, the positive and negative roots of the quadratic equation

$$
\frac{1}{2} \sigma_{R}^{2} \phi(\phi-1)+\mu_{R} \phi-r+\mu_{j}=0 .
$$


Condition (A.17) implies that $B=0$. Conditions (A.15) and (A.16) can be written

$$
A R^{\beta}=\xi V(R, 1)-K R \text { and } \beta A R^{\beta-1}=\xi V_{R}(R, 1)-K .
$$

Rearranging these equations gives

$$
A=\left(R^{*}\right)^{-\beta}[\xi V(R, 1)-K R] \quad \text { and } \quad R^{*}=\frac{\beta}{\beta-1} \frac{\xi[(K+Q) \alpha-Q]}{\xi[K+\alpha \omega(K+Q)]-K} .
$$

\section{Appendix B. Central-planning formulation}

One interesting feature of the Nash equilibrium described in Proposition 1 is that it can be formulated as a surplus-maximization problem for a central planner. The objective of the planner is to determine the restructuring policy that maximizes the combined surplus $G^{\mathrm{C}}(X, Y)$. The value of the restructuring option for the central planner, denoted by $O^{\mathrm{P}}(X, Y)$, satisfies the partial differential equation

$$
r O^{\mathrm{P}}=\mu_{X} X O_{X}^{\mathrm{P}}+\mu_{Y} Y O_{Y}^{\mathrm{P}}+\frac{1}{2} \sigma_{X X}^{2} X^{2} O_{X X}^{\mathrm{P}}+\rho \sigma_{X} \sigma_{Y} X Y O_{X Y}^{\mathrm{P}}+\frac{1}{2} \sigma_{Y}^{2} Y^{2} O_{Y Y}^{\mathrm{P}},
$$

subject to the value-matching and smooth-pasting conditions

$$
\begin{gathered}
\left.O^{\mathrm{P}}(X, Y)\right|_{X=\pi^{\mathrm{B}}(Y)}=\left.G^{\mathrm{C}}(X, Y)\right|_{X=\pi^{\mathrm{P}}(Y)}, \\
\left.O_{X}^{\mathrm{P}}(X, Y)\right|_{X=\pi^{\mathrm{B}}(Y)}=\left.G_{i}^{\mathrm{C}}(X, Y)\right|_{X=\pi^{\mathrm{P}}(Y)}, \\
\left.O_{Y}^{\mathrm{P}}(X, Y)\right|_{X=\pi^{\mathrm{B}}(Y)}=\left.G_{j}^{\mathrm{C}}(X, Y)\right|_{X=\pi^{\mathrm{P}}(Y)},
\end{gathered}
$$

and the boundary condition

$$
\lim _{X / Y \rightarrow 0} \frac{O^{\mathrm{P}}(X, Y)}{X}=0 .
$$

Using the same change of numéraire as above yields a restructuring policy identical to that described in Proposition 1.

\section{Appendix C. Abnormal returns}

In the absence of competition, abnormal returns to bidding shareholders at the time of the takeover announcement are given by

$$
A R_{\mathrm{B}}(\tau)=\frac{\frac{1}{2}\left[O^{\mathrm{B}}(X, Y ; 1)-O^{\mathrm{B}}\left(X, Y ; 1-\sigma_{\omega}\right)\right]}{B\left(\tau_{-}\right)} .
$$


Using the expression derived for the option to merge and after simplifications we get

$$
A R_{\mathrm{B}}(\tau)=\frac{\frac{K(\alpha(K+Q)-Q)}{Q+K}-\frac{K(\alpha(K+Q)-Q)}{\left(1-\sigma_{\omega}\right) Q+K}\left(1-\sigma_{\omega}\right)^{\beta}}{2 K \beta+\frac{K(\alpha(K+Q)-Q)}{Q+K}+\frac{K(\alpha(K+Q)-Q)}{\left(1-\sigma_{\omega}\right) Q+K}\left(1-\sigma_{\omega}\right)^{\beta}} .
$$

Similarly, abnormal returns to target shareholders at the time of the takeover announcement are given by

$$
A R_{\mathrm{T}}(\tau)=\frac{\frac{1}{2}\left[O^{\mathrm{T}}(X, Y ; 1)-O^{\mathrm{T}}\left(X, Y ; 1-\sigma_{\omega}\right)\right]}{T\left(\tau_{-}\right)} .
$$

Using the expression derived for the option to merge and after simplifications we get

$$
\begin{aligned}
& A R_{\mathrm{T}}(\tau)=\frac{Q(K+Q) \alpha+Q K}{Q+K}-\frac{\left(1-\sigma_{\omega}\right) Q(K+Q) \alpha+Q K}{\left(1-\sigma_{\omega}\right) Q+K}\left(1-\sigma_{\omega}\right)^{\beta} \\
& 2 Q(\beta-1)+\frac{Q(K+Q) \alpha+Q K}{Q+K}+\frac{\left(1-\sigma_{\omega}\right) Q(K+Q) \alpha+Q K}{(1-\sigma) Q+K}\left(1-\sigma_{\omega}\right)^{\beta}
\end{aligned} .
$$

Using these expressions, it is immediately seen that $A R_{\mathrm{T}}(\tau)>A R_{\mathrm{B}}(\tau)$ when $K \geqslant Q$.

\section{Appendix D. Timing of takeovers when $\alpha_{1} \neq \alpha_{2}$}

Suppose $\alpha_{1} \neq \alpha_{2}$. Then there exists a critical point $\bar{R}$ such that if $R<(>) \bar{R}$ then bidder 2 (1) is stronger. Consequently, the value of $R$ at the start of the game determines which bidder wins the takeover. In particular, assume that $K_{1}=K_{2}$, $\alpha_{1}>\alpha_{2}$, and $\omega_{1}<\omega_{2}$. Under these assumptions, we have $R_{2}^{*}=\beta /\left[\omega_{2}(\beta-1)\right]<\beta /\left[\omega_{1}(\beta-1)\right]=R_{1}^{*}$. Moreover, it can be immediately seen that

$$
\bar{R}=\frac{\alpha_{1}-\alpha_{2}}{\alpha_{1} \omega_{1}-\alpha_{2} \omega_{2}} \text {. }
$$

We then have the two following cases:

1. Suppose that the starting value of the ratio of core business valuations is lower than $\bar{R}$. If $R_{2}^{*}<\bar{R}$, and bidder 1 is weak, then bidder 2 wins the takeover and competition does not affect the timing or the terms of takeovers. In particular, the takeover occurs the first time $R$ reaches $R_{2}^{*}$. Otherwise, competition affects the timing and terms of takeovers. Specifically, the takeover takes place the first time $\left(R_{t}\right)_{t \geqslant 0}$ reaches the threshold $R_{b e 1}$ conditional on $R_{b e 1}<\bar{R}$, where $R_{b e 1}$ is the ratio of core business valuations for which the breakeven share of bidder 1 is equal to the equilibrium share of the target.

2. Suppose instead that the starting value of the ratio of core business valuations is larger than $\bar{R}$. If the takeover happens for $R>\bar{R}$, then it takes place the first time $\left(R_{t}\right)_{t \geqslant 0}$ reaches the threshold $R^{*}=\min \left[R_{1}^{*}, R_{b e 2}\right]$, where $R_{b e 2}$ is the ratio of core 
business valuations for which the breakeven share of bidder 2 is equal to the equilibrium share of the target. In this equation the min function takes a value equal to its first argument when the losing bidder is weak and a value equal to its second argument when the losing bidder is strong. In the latter case, competition speeds up the takeover process and erodes the ownership stake of bidding shareholders.

The above argument shows that when $\alpha_{1} \neq \alpha_{2}$ and $\min \left[R_{2}^{*}, R_{b e 1}\right]<\bar{R}$, takeovers happen in "up" as well as "down" states, but they are undertaken by different types of firms. In the two different regions of exercise, each firm decides on the optimal timing, subject to the threat of competition and the premium that is demanded by the target.

\section{References}

Andrade, G., Stafford, E., 2004. Investigating the economic role of mergers. Journal of Corporate Finance $10,1-36$.

Andrade, G., Mitchell, M., Stafford, E., 2001. New evidence and perspectives on mergers. Journal of Economic Perspectives 15, 103-120.

Grenadier, S., 1999. Information revelation through option exercise. Review of Financial Studies 12, 95-129.

Grenadier, S., 2002. Option exercise games: an application to the equilibrium investment strategies of firms. Review of Financial Studies 15, 691-721.

Grossman, S., Hart, O., 1980. Takeover bids, the free-rider problem and the theory of the firm. Bell Journal of Economics 11, 42-64.

Jensen, M., 1986. Agency costs of free cash flow, corporate finance and takeovers. American Economic Review 76, 323-329.

Lambrecht, B., 2004. The timing and terms of mergers motivated by economies of scale. Journal of Financial Economics 72, 41-62.

Lambrecht, B., Perraudin, W., 2003. Real options and preemption under incomplete information. Journal of Economic Dynamics and Control 27, 619-643.

Margrabe, W., 1978. The value of the option to exchange one asset for another. Journal of Finance 33, $177-186$.

Novy-Marx, R., 2003. An equilibrium model of investment under uncertainty. Unpublished working paper. University of Chicago.

Roll, R., 1986. The hubris hypothesis of corporate takeovers. Journal of Business 59, 197-216.

Schwert, W., 2000. Hostility in takeovers: in the eyes of the beholder. Journal of Finance 55, 2599-2640.

Shleifer, A., Vishny, R., 2003. Stock market driven acquisitions. Journal of Financial Economics 70, $295-311$. 